\title{
Over kanserinde nötrofil/lenfosit, trombosit/lenfosit, CRP/Albümin oranları ile klinikopatolojik özellikler ve sağkalım arasındaki ilişki
}

\author{
Relationship between neutrophil/lymphocyte, platelet/lymphocyte, CRP/Albumin ratio \\ and survival in ovarian cancer
}

\author{
Burcu Yapar Taşköylü, Esin Avcı, Atike Gökçen Demiray, Serkan Değirmencioğlu, Gamze Gököz \\ Doğu, Arzu Yaren, Ahmet Ergin, Derya Kılıç, Canan Karan, Burçin Çakan Demirel, Tolga Doğan, \\ Melek Özdemir
}

\section{Öz}

Amaç: Over kanseri jinekolojik kanserler arasında en yüksek ölüm oranına sahip olan kanserdir. Birçok kanserde inflamasyon temelli skorlar olan nötrofil lenfosit oranının (NLR), trombosit lenfosit oranının (PLR), CRP albümin oranının (CRP/Alb) prognoz üzerine etkisi gösterilmiştir. Biz de bu çalışmada NLR, PLR, CRP/Alb oranlarının over kanserinin prognozu üzerine olan etkisini değerlendirmeyi amaçladık.

Gereç ve yöntem: Çalışmamıza Eylül 2014-Aralık 2020 tarihleri arasında Pamukkale Üniversitesi Tıp Fakültesi Tıbbi Onkoloji Bilim Dalı polikliniğine başvuran over karsinom tanılı evreleri 1 ile 4 arasında değişen toplam 124 hasta dâhil edildi. NLR, PLR, CRP/Alb kesme noktaları ROC analizi ile yapıldı.

Bulgular: Hastalarımızın medyan yaşı 56 (sınırlar 24-84) idi. NLR oranı 63 hastada(\%50), PLR oranı 56 hastada (\%45), CRP/Alb oranı 61 hastada (\%49) kesme değerine göre yüksek saptandı. PLR değeri ile progresyon sağkalım arasında istatistiksel olarak anlamlı ilişki yokken, genel sağkalımla istatistiksel olarak anlamlı iliş̧i bulunmaktaydı $(p=0,01)$. PLR değeri yüksek olanlarda medyan genel sağkalım 23 ay iken PLR değeri düşük olanlarda 45 ay olarak saptandı. CRP/Alb oranının ise hem progresyonsuz sağkalım hem de genel sağkalım ile istatistiksel olarak anlamlı ilişkisi mevcuttu $(p=0,011 ; p=0,008)$. CRP/Alb değeri düşük olanlarda daha uzun progresyonsuz sağkalım ve genel sağkalım olduğu saptandı.

Sonuç: Diğer kanser tiplerinde olduğu gibi over kanserinde de inflamasyon belirteçlerinin kanser progresyonu üzerine dolayısıyla prognoza olan etkisi dikkat çekmektedir. PLR oranının genel sağkalımla, CRP/Alb oranının ise hem genel sağkalım hemde progresyonsuz sağkalımla istatistiksel olarak anlamlı bir ilişkisi olduğunu gösterdik. Bu oranların gelecekte farklı tedavi gruplarını oluştururken hastaların seçiminde yardımcı olabileceği kanısındayız.

Anahtar kelimeler: Over kanseri, inflamasyon, prognoz.

Yapar Taşköylü B, Avcı E, Gökçen Demiray A, Değirmencioğlu S, Gököz Doğu G, Yaren A, Ergin A, Kılıç D, Karan C, Çakan Demirel B, Doğan T, Özdemir M. Over kanserinde nötrofil/lenfosit, trombosit/lenfosit, CRP/ Albümin oranları ile klinikopatolojik özellikler ve sağkalım arasındaki ilişki. Pam Tıp Derg 2021;14:666-674.

\footnotetext{
Burcu Yapar Taşköylü, Dr. Öğr. Üye. Pamukkale Üniversitesi Tıp Fakültesi, İç Hastalıkları Anabilim Dalı, Tıbbı Onkoloji Bilim Dalı, Denizli, Türkiye, e-posta: drburcuyapar@gmail.com (https://orcid.org/0000-0003-4755-2753) (Sorumlu Yazar)

Esin Avcı, Dr. Öğr. Üye. Pamukkale Üniversitesi Tıp Fakültesi, Tıbbi Biyokimya Anabilim Dalı, Denizli, Türkiye, e-posta: eavci@pau.edu.tr (https://orcid.org/0000-0002-9173-0142)

Atike Gökçen Demiray, Dr. Öğr. Üye. Pamukkale Üniversitesi Tıp Fakültesi, İç Hastalıkları Anabilim Dalı, Tıbbı Onkoloji Bilim Dalı, Denizli, Türkiye, e-posta: gokcenakaslan@gmail.com (https://orcid.org/0000-0003-4397-5468)

Serkan Değirmencioğlu, Doç. Dr. Pamukkale Üniversitesi Tıp Fakültesi, İç Hastalıkları Anabilim Dalı, Tıbbı Onkoloji Bilim Dalı, Denizli, Türkiye, e-posta: drserkandeg@hotmail.com (https://orcid.org/0000-0002-1213-2778)

Gamze Gököz Doğu, Prof. Dr. Pamukkale Üniversitesi Tıp Fakültesi, İç Hastalıkları Anabilim Dalı, Tıbbı Onkoloji Bilim Dalı, Denizli, Türkiye, e-posta: ggd2882@gmail.com (https://orcid.org/0000-0002-8142-0362)

Arzu Yaren, Prof. Dr. Pamukkale Üniversitesi Tıp Fakültesi, İç Hastalıkları Anabilim Dalı, Tıbbı Onkoloji Bilim Dalı, e-posta: arzu_yaren@yahoo. com (https://orcid.org/0000-0002-1436-8650)

Ahmet Ergin, Prof. Dr. Pamukkale Üniversitesi Tıp Fakültesi, Halk Sağlığı Anabilim Dalı, Denizli, Türkiye, e-posta: aergin@pau.edu.tr (https:// orcid.org/0000-0001-5236-7507)

Derya Kılıç, Dr. Öğr. Üye. Pamukkale Üniversitesi Tıp Fakültesi, Kadın Hastalıkları ve Doğum Anabilim Dalı, Denizli, Türkiye e-posta: deryakilic. md@gmail.com (https://orcid.org/0000-0001-8003-9586)

Canan Karan, Arş. Gör. Pamukkale Üniversitesi Tıp Fakültesi, İç Hastalıkları Anabilim Dalı, Tıbbı Onkoloji Bilim Dalı, Denizli, Türkiye, e-posta: canankaran@hotmail.com (https://orcid.org/0000-0002-1293-2046)

Burçin Çakan Demirel, Arş. Gör. Pamukkale Üniversitesi Tıp Fakültesi, İç Hastalıkları Anabilim Dalı, Tıbbı Onkoloji Bilim Dalı, e-posta: brcn ckn@hotmail.com (https://orcid.org/0000-0003-0734-0692)

Tolga Doğan, Arş. Gör. Pamukkale Üniversitesi Tıp Fakültesi, İç Hastalıkları Anabilim Dalı, Tıbbı Onkoloji Bilim Dalı, Denizli, Türkiye, e-posta:dr_ tolgadogan94@yahoo.com (https://orcid.org/0000-0003-1281-942X)

Melek Özdemir, Arş. Gör. Pamukkale Üniversitesi Tıp Fakültesi, İç Hastalıkları Anabilim Dalı, Tıbbı Onkoloji Bilim Dalı, e-posta: melekozdemir@ hotmail.com (https://orcid.org/0000-0003-1894-9743)
} 


\begin{abstract}
Purpose: Ovarian cancer has the highest mortality rate among gynecological cancers. Inflammation-based scores such as neutrophil lymphocyte ratio (NLR), platelet lymphocyte ratio (PLR), CRP albumin ratio (CRP/Alb) have been shown to have an effect on prognosis in most cancers. In this study, we aimed to evaluate the effect of NLR, PLR, CRP/Albumin ratios on the prognosis of ovarian cancer.

Material and method: A total of 124 patients with ovarian carcinoma diagnosed stages ranging from 1 to 4 were included in our study who applied to Pamukkale University Medical Faculty Medical Oncology Outpatient Clinic between September 2014 and December. NLR, PLR, CRP/Alb cut-off points were made by ROC analysis. Results: The median age of our patients was 56 (range 24-84). The NLR rate was higher in 63 patients (50\%), the PLR rate in 56 patients (45\%), and the CRP/Alb ratio in 61 patients (49\%) compared to the cut-off value. While there was no statistically significant relationship between PLR value and progression free survival, there was a statistically significant relationship with overall survival $(p=0.01)$. While the median overall survival was 23 months in those with high PLR values, it was 45 months in those with low PLR values. The CRP/Alb ratio had a statistically significant relationship with both progression free survival and overall survival $(p=0.011 ; p=0.008)$. Longer progression free survival and overall survival were found in those with low CRP/Alb values.

Conclusion: As in other cancer types, the effect of inflammation markers on cancer progression and thus on prognosis is remarkable in ovarian cancer. We showed that the PLR ratio has a statistically significant relationship with overall survival and the CRP/Alb ratio with both overall survival and progression free survival. We are of the opinion that these rates may help in the selection of patients while creating different treatment groups in the future.
\end{abstract}

Key words: Ovarian cancer, inflammation, prognosis.

Yapar Taskoylu B, Avci E, Gokcen Demiray A, Degirmencioglu S, Gokoz Dogu G, Yaren A, Ergin A, Kılıc D, Karan C, Cakan Demirel B, Dogan T, Ozdemir M. Relationship between neutrophil/lymphocyte, platelet/lymphocyte, CRP/Albumin ratio and survival in ovarian cancer. Pam Med J 2021;14:666-674.

\section{Giriş}

Over kanseri kadınlarda onuncu sırada görülmekle birlikte, kansere bağlı ölümlerde beşinci sırada yer almaktadır [1]. Hastaların çoğu tanı anında ileri evrede bulunmaktadır. Sitoreduktif cerrahi ve gerekli durumda adjuvan kemoterapi over kanserinde standart tedaviyi oluşturmaktadır [2]. Cerrahi tekniklerde ilerlemelerin olması, neoadjuvan kemoterapinin uygulanması, intraperitoneal hipertermik kemoterapinin uygulanmasına rağmen uzun dönem sağkalım sonuçları istenilen düzeylere ulaşamamıştır. Over kanserinde prognoz değişkenlik gösterebilmektedir. Bazı hastaların prognozu çok iyi olmakta, bazı hastalarda ise agresif bir seyir izlenmektedir. Bu nedenle prognozu tahmin etmeye yardımcı olabilecek belirteçlere intiyaç bulunmaktadır. En önemli prognostik faktörler tanı anında evre ve rezidüel tümör volümüdür [3]. Histopatolojik özellikler ve CA 125 prognozu belirlemekle birlikte kandaki inflamasyon göstergeleri de prognozu ön gördürebilmektedir. Endometriozis ve pelvik inflamatuvar hastalığı olanlarda over kanseri insidansında artış olduğu bildirilmiştir [4].

Son yıllardakiçalışmalarkansergelişmesinde inflamasyonun kanser gelişimindeki moleküler temeline odaklanmaktadır. Kanser hücrelerinin proliferasyonu, anjiogenez ve metastaz yapmaları sistemik inflamasyonu tetiklemektedir [5]. Kanser hücrelerinden interlökin 2 (IL-2), interlökin 6 (IL-6), interlökin 10 (IL-10), tümör nekrozis faktör alfa (TNF- $\alpha$ ), vasküler endotelyal büyüme faktörü (VEGF) gibi mediatörlerin salınmasından sonra sistemik inflamatuvar yanıt oluşmaktadır [6]. TNF- $\alpha$ ve IL-10 yüksek olması lenfosit sayısını düşürmektedir [7]. Lenfosit sayısının azalması $T$ lenfosit aracılı anti tümör yanıtı azaltmakta ve böylece kanser progresyonu oluşmaktadır.

Nötrofil lenfosit oranının (NLR) ve trombosit lenfosit oranının (PLR) kolorektal, mide, meme ve akciğer, özafagus kanserlerin de prognozla ve mortalite ile ilişkili olduğu gösterilmiştir [8-12]. Over kanserinde de NLR, PLR oranlarının daha yüksek olması ile daha kötü progresyonsuz sağkalım ve genel sağkalımla ilişkili olduğu gösterilmiştir $[13,14]$. CRP inflamasyon sonrasında hepatositlerden salınan bir akut faz reaktanıdır [15]. Hefler ve ark. [16] yaptığı çalışmada over kanserli hastalarda CRP'nin yüksek olması kötü prognozla ilişkili bulunmuştur. Hipoalbuminemi de sistemik inflamatuvar yanıtla ilişsilidir. CRP Albümin (CRP/Alb) oranıda inflamasyon durumunu yansıtmaktadır. Yüksek CRP de over kanseri ile ilişkili olduğu bildirilmiştir [17]. 


\section{Gereç ve yöntem}

Pamukkale Üniversitesi Tıp Fakültesi, Tıbbi Onkoloji Anabilim Dalı'nda 2011-2020 yılları arasında tedavi edilen 124 over karsinom tanılı hasta çalışmaya alındı. Hastaların demografik verileri, alınan tümör tipleri ve kemoterapiler hasta dosyalarından ve hastane bilgi işlem sisteminden kaydedildi. Çalışma sonunda sağkalım süreleri istatistiksel olarak analiz edildi. Bu çalışma Pamukkale Üniversitesi Tıp Fakültesi Girişimsel Olmayan Klinik Araştırmalar Etik Kurulu tarafından onaylandı. Katılımcıların nötrofil, lenfosit, platelet mutlak sayıları ile, CRP ve albümin düzeyleri geriye dönük olarak Laboratuvar Bilgi Sisteminden alındı. Hemogram parametrelerinin analizi Mindray CAL 8000 (Shangai, China) oto analizöründe elektriksel empedans ve optik dansite yöntemi ile çalışılırken, CRP ve albümin düzeyleri ise elektrokemilüminesan yöntem ile Cobas 702 (Roche Diagnostics, Manheim, Germany) analizörlerinde analiz edilmiştir. CRP $\mathrm{mg} / \mathrm{L}$, Albümin g/L olarak ifade edilirken, hücre sayıları mikrolitrede $10^{3}$ olarak ifade edilmiştir. ROC curve analizi yapılarak NLR, PLR ve CRP/Alb değerleri için kesme noktası belirlendi. NLR için 4,25, PLR için 0,19, CRP/Alb için 0,41 olarak kabul edildi.

\section{İstatistiksel yöntem}

İstatistiksel analiz için SPSS v.23 yazılım paketleri kullanılmıştır. Tanımlayıcı istatistikler ortalama ve yüzde olarak verildi. Gruplar arasındaki farklılıkların önemi Mann-Whitney $U$ testi ile değerlendirildi. Progresyonsuz ve genel sağkalım Kaplan-Meier yöntemi kullanılarak hesaplanmıştır. İstatistiksel anlamlılık için Log rank değeri alınmış olup $p<0,05$ kabul edilmiştir. Multivariet analiz Cox analiz yöntemi kullanılarak yapılmıştır.

\section{Bulgular}

Biz bu çalışmamızda over kanseri tanılı Evre 1-4 arasında değişen toplam 124 hastayı inceledik. Tanı anında bakılan nötrofil/lenfosit Oranı, trombosit/lenfosit Oranı, CRP/Alb oranı ve sağkalım ile ilgili prognostik bilgiler retrospektif olarak hasta dosyalarından ve hasta bilgi işlem sisteminden kaydedildi. Hastaların ortanca yaşı 56 (sınırlar: 24-84 yıl) olarak saptandı. Hastalarımızdan $54(\% 43,5)$ 'ü evre 1 ve 2, $70(\% 56,5)$ 'i evre 3-4 idi. Hastalarımızın 92 (\%74,2)'si seröz histolojide idi. Histolojik gradlarına baktığmızda 98 (\%79) hasta yüksek gradlı idi. NLR oranı hastarın \%50,8'sinde PLR oranı \%54,8'sinde CRP/Alb oranı ise \%50,8'inde yüksek saptandı (Tablo 1).

NLR oranının histopatolojik ve klinik belirteçlerle ilişkisinin incelenmesinde, elli yaşın üzerinde olan hastalarda NLR oranının istatistiksel anlamlılığa ulaşmasa da rakamsal olarak farklılığı mevcuttu $(p=0,09)$. Platin duyarlı hastalarda NLR oranı istatiksel olarak daha anlamlı olmasada rakamsal olarak farklılık mevcuttu $(p=0,077)$. Platin duyarlı olanlarda daha yüksek NLR oranı olduğunu saptandı.

PLR oranının histopatolojik ve klinik belirteçlerle ilişkisini incelediğimizde yaş, evre, grad, platin duyarlılık ile istatiksel olarak anlamlı bir ilişki saptanmadı. CRP/Alb oranının ise evre ile istatiksel olarak anlamlı ilişkisi mevcuttu $(p=0,016)$. İleri evrelerde daha yüksek CRP/Alb değeri mevcuttu. Yaş, grad ve platin duyarlılık ile istatistiksel olarak anlamlı bir ilişkisi bulunmadı (Tablo 2). NLR, PLR, CRP/Alb oranlarının progresyonsuz sağkalım ve genel sağkalım ile ilişkisini incedik. CRP/Alb oranının, platin duyarlılığın ve evrenin progresyonsuz sağkalım ile istatistiksel olarak anlamlı ilişkisi mevcuttu (sırasıyla $p=0,011 ; p<0,001 ; p<0,001$ ). NLR ve PLR oranlarının, yaşın, gradın progresyonsuz sağkalım ile istatiksel olarak anlamalı ilişkisi yoktu (sırasıyla $p=0,135 ; \quad p=0,291$ ). PLR ve CRP/Alb oranının ise genel sağkalımla istatiksel olarak anlamlı ilişkisi mevcuttu (sırasıyla $p=0,011 ; p=0,008)$. NLR oranınının ise genel sağkalımla istatiksel anlamlılığa yakın bir ilişkisi mevcuttu $(p=0,065)$ (Tablo 3 ). Multivariet analizde de evre ve platin duyarlılık progresyonsuz sağkalım üzerine istatiksel olarak anlamlı saptandı $(p<0,001)$ (Tablo 4). CRP/Alb oranının hem progresyonsuz sağkalımla hem de genel sağkalımla ilişkisi Kaplan-Meier grafiği ile gösterilmiştir (Şekil 1, 2). 
Tablo 1. Hasta özellikleri

\begin{tabular}{|c|c|c|c|}
\hline & & $\mathrm{n}$ & $\%$ \\
\hline \multirow[t]{3}{*}{ Yaş } & \multicolumn{3}{|c|}{ medyan 56 (sınırlar: 24-84 yıl) } \\
\hline & $\leq 50$ & 37 & 29,8 \\
\hline & $>50$ & 87 & 70,2 \\
\hline \multirow[t]{2}{*}{ Evre } & $1-2$ & 54 & 43,5 \\
\hline & $3-4$ & 70 & 56,5 \\
\hline \multirow[t]{6}{*}{ Histoloji } & Seröz & 92 & 74,2 \\
\hline & Borderline & 5 & 4 \\
\hline & Granuloza & 9 & 7,3 \\
\hline & Müsinöz & 7 & 5,6 \\
\hline & Endometrioid & 5 & 4 \\
\hline & Berrak hücreli & 6 & 4,8 \\
\hline \multirow[t]{2}{*}{ Grad } & Düşük (G1-G2) & 26 & 21,0 \\
\hline & Yüksek (G3) & 98 & 79,0 \\
\hline \multirow[t]{2}{*}{ NLR } & Düşük & 61 & 49,2 \\
\hline & Yüksek & 63 & 50,8 \\
\hline \multirow[t]{2}{*}{ PLR } & Düşük & 56 & 45,2 \\
\hline & Yüksek & 68 & 54,8 \\
\hline \multirow[t]{2}{*}{ CRP/Alb } & Düşük & 61 & 49,2 \\
\hline & Yüksek & 63 & 50,8 \\
\hline
\end{tabular}

*NLR: Nötrofil/Lenfosit oranı, PLR: Trombosit/Lenfosit oranı, CRP/Alb: CRP/Albümin

Tablo 2. NLR, PLR, CRP/Alb oranları ile patolojik ve klinik özelliklerinin ilişkisi

\begin{tabular}{|c|c|c|c|c|c|c|c|c|c|c|}
\hline & & \multicolumn{3}{|l|}{ NLR } & \multicolumn{3}{|l|}{ PLR } & \multicolumn{3}{|c|}{ CRP/Alb } \\
\hline & & düşük & yüksek & $p$ & düşük & yüksek & $p$ & düşük & yüksek & $p$ \\
\hline \multirow[t]{2}{*}{ Yaş } & $\leq 50$ & 14 & 23 & 0,09 & 12 & 25 & 0,061 & 20 & 17 & 0,51 \\
\hline & $>50$ & 47 & 40 & & 44 & 43 & & 41 & 45 & \\
\hline \multirow[t]{2}{*}{ Evre } & $1-2$ & 26 & 28 & 0,49 & 26 & 28 & 0,34 & 33 & 21 & 0,016 \\
\hline & $3-4$ & 35 & 35 & & 30 & 40 & & 28 & 42 & \\
\hline \multirow[t]{2}{*}{ Grad } & $\begin{array}{l}\text { Düşük (G1- } \\
\text { G2) }\end{array}$ & 13 & 13 & 0,55 & 12 & 14 & 0,54 & 11 & 15 & \\
\hline & $\begin{array}{l}\text { Yüksek } \\
\text { (G3) }\end{array}$ & 48 & 50 & & 44 & 54 & & 50 & 48 & 0,28 \\
\hline \multirow[t]{2}{*}{ Platin } & Duyarlı & 55 & 50 & 0,077 & 49 & 56 & 0,29 & 54 & 51 & 0,17 \\
\hline & Dirençli & 6 & 13 & & 7 & 12 & & 7 & 12 & \\
\hline
\end{tabular}

*Mann Whitney $U$ and Kruskal-Walles testleri kullanılmıştır

$p<0,05$ istatistiksel olarak anlamlı kabul edilmiştir

*NLR: Nötrofil/Lenfosit oranı, PLR: Trombosit/Lenfosit oranı, CRP/Alb: CRP/Albümin 
Tablo 3. Progresyonsuz sağkalım ve genel sağkalımı etkileyen faktörler

\begin{tabular}{|c|c|c|c|c|c|}
\hline \multicolumn{2}{|l|}{ Faktörler } & \multicolumn{2}{|l|}{ PFS(ay) } & \multicolumn{2}{|l|}{ OS(ay) } \\
\hline & & $\begin{array}{l}\text { Medyan } \\
(\% 25-\% 75)\end{array}$ & $p$ & $\begin{array}{l}\text { Medyan } \\
(\% 25-\% 75)\end{array}$ & $p$ \\
\hline \multirow[t]{2}{*}{ Yaş } & $\leq 50$ & $75(--25)$ & 0,10 & $48(77-21)$ & 0,15 \\
\hline & $>50$ & $32(117-14)$ & & $28(63-10)$ & \\
\hline \multirow[t]{2}{*}{ Evre } & $1-2$ & $117(--88)$ & $<0,001$ & $45(72-19)$ & 0,172 \\
\hline & $3-4$ & $22(52-11)$ & & $32(61-10)$ & \\
\hline \multirow[t]{2}{*}{ Grad } & G1-G2 & $65(--27)$ & 0,456 & $37(62-15)$ & 0,758 \\
\hline & G3 & $38(117-14)$ & & $33(67-14)$ & \\
\hline \multirow[t]{2}{*}{ Platin duyarlılık } & Dirençli & $11(19-62)$ & $<0,001$ & $27(45-14)$ & 0,495 \\
\hline & Duyarlı & $77(--23)$ & & $39(67-14)$ & \\
\hline \multirow[t]{2}{*}{ NLR } & Düşük & $75(--20)$ & 0,135 & $45(70-19)$ & 0,065 \\
\hline & Yüksek & $32(88-14)$ & & $24(49-10)$ & \\
\hline \multirow[t]{2}{*}{ PLR } & Düşük & $65(--18)$ & 0,291 & $45(77-19)$ & 0,016 \\
\hline & Yüksek & $32(88-16)$ & & $23(52-11)$ & \\
\hline \multirow[t]{2}{*}{ CRP/Alb } & Düşük & $75(-22)$ & 0,011 & $46(83-20)$ & 0,008 \\
\hline & Yüksek & $27(77-12)$ & & $22(49-9)$ & \\
\hline
\end{tabular}

${ }^{*} p$ değerleri Kaplan Meier analizi Log Rank $p$ değerinden elde edilmiştir

$p<0,05$ istatistiksel olarak anlamlı kabul edilmiştir

*PFS: Progresyonsuz sağkalım, OS: Genel Sağkalım, NLR: Nötrofil/Lenfosit oranı

PLR: Trombosit/Lenfosit oranı, CRP/Alb: CRP/Albümin

Tablo 4. Progresyonsuz sağkalım ve genel sağkalımı etkileyen faktörlerin multivariet analizi

\begin{tabular}{lllll}
\hline & & Hazard oranı & $\% 95, \mathrm{Cl}$ & $p$ \\
\hline PFS & & & \\
& Evre & 0,177 & $0,080-0,391$ & $<0,001$ \\
& Platin duyarlılık & 3,272 & $1,720-6,225$ & $<0,001$ \\
& NLR & 0,659 & $0,283-1,533$ & 0,333 \\
& PLR & 0,853 & $0,379-1,918$ & 0,700 \\
& CRP/Alb & 1,008 & $0,528-1,925$ & 0,981 \\
& & & \\
& Evre & 0,807 & $0,513-1,269$ & 0,353 \\
& Platin duyarlılık & 1,095 & $0,618-1,941$ & 0,756 \\
& NLR & 0,932 & $0,537-1,618$ & 0,803 \\
& PLR & 0,654 & $0,382-1,119$ & 0,121 \\
& CRP/Alb & 0,673 & $0,427-1,060$ & 0,087 \\
\hline
\end{tabular}

* $p$ değerleri Cox multivariate analizi ile elde edilmiştir $p<0,05$ istatistiksel olarak anlamlı kabul edilmiştir 


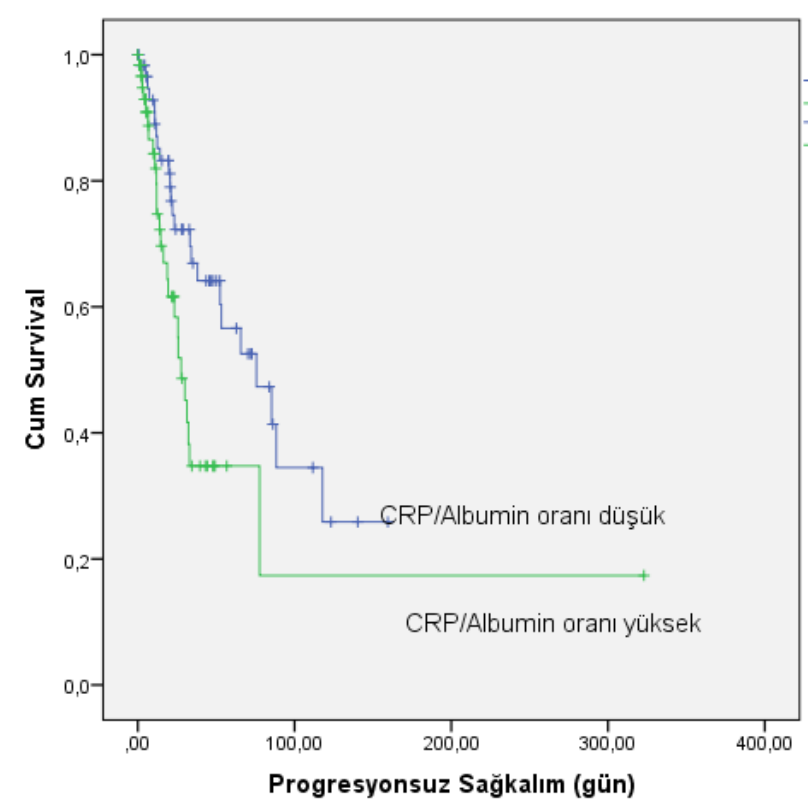

Şekil 1. CRP/Alb oranının progresyonsuz sağkalım ile ilişkisini gösteren Kaplan-Meier grafiği $(p=0,011)$

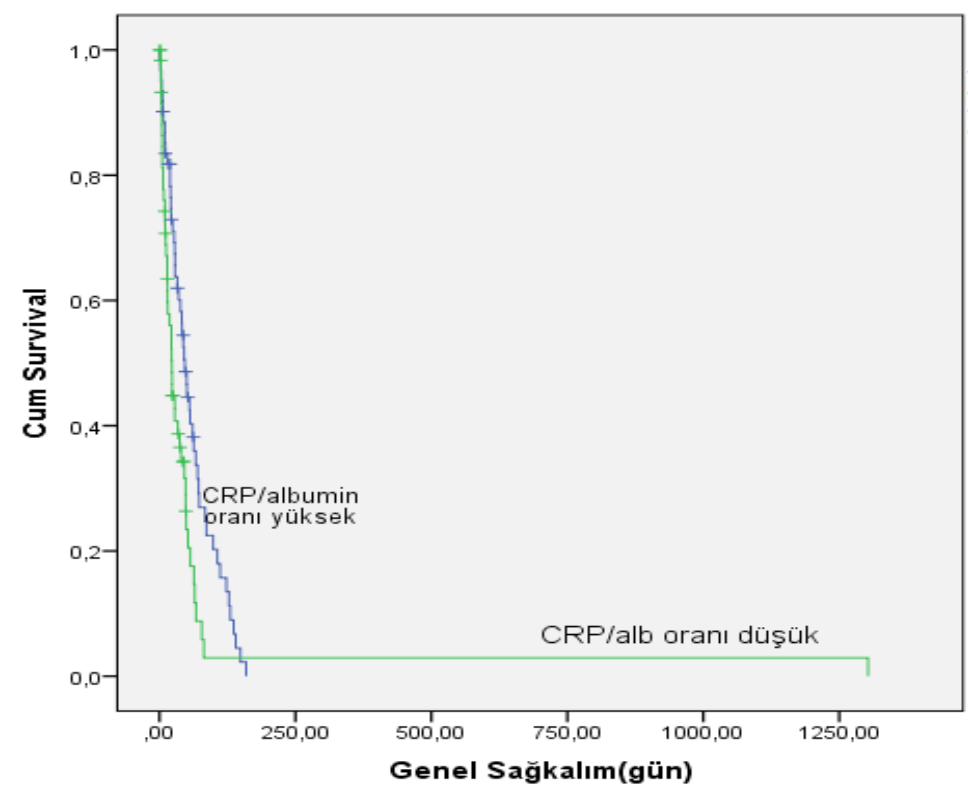

Şekil 2. CRP/Alb oranının genel sağkalım ile ilişkisini gösteren Kaplan-Meier grafiği $(p=0,008)$

\section{Tartışma}

Over kanseri jinekolojik kanserler içinde en sık ölüme neden olan kanserdir. Beş yıllık sağkalım oranları \%31 ile \%53 arasında değişmektedir. İnflamasyonun birçok kanserle ilişkisi gösterilmiştir [18]. Milne ve ark. [19] yaptığı çalışmada over kanseri tanısı alan hastaların lenfosit değerlerinin iki yıl önce yapılan testlerdeki lenfosit değerlerine göre daha düşük olduğunu göstermişlerdir. Evre ne kadar ileri ise lenfosit değerinde daha fazla oranda düşme olduğunu saptamışlardır. NLR oranını hastarımızın \%50,8'sinde, PLR oranı $\% 54,8$ 'sinde, CRP/Alb oranı ise \%50,8'inde yüksek saptadık. Elli yaşın üzerinde olan hastalarda NLR oranı istatistiksel anlamlıığa ulaşmasa da rakamsal olarak farklılık mevcuttu $(p=0,09)$. Williams ve ark. [20] yaptığı çalışmada da yaş ile NLR arasında ilişki saptamamışlardır. Platin duyarlı hastalarda NLR oranı istatistiksel olarak daha anlamlı saptandı $(p=0,077)$. Literatür 
incelemesinde platin duyarlılık ile bu oranların ilişkisini inceleyen makaleye rastlanmadı.

NLR oranınının genel sağkalımla istatiksel anlamlılığa yakın bir ilişkisi mevcuttu $(p=0,065)$. Wang ve ark. [21] yaptığı çalışma da da NLR ve albümin değerinin PFS ve OS arasında anlamlı ilişkili olduğunu bildirmişlerdir. Yin ve ark. [22] yaptığı metanalize on çalışma ve 2919 hasta dahil edilmiştir. Hem univariet hem multivariet analizde NLR oranı yüksek hastalarda kontrol grubuna göre daha kısa progresyonsuz sağkalım $(H R=1,36, \% 95, C l=1,17-1,57)$ ve genel sağkalım $(H R=1,34, \% 95, C l=1,16-1,54)$ olduğu saptanmıştır. PLR oranınınında yüksek olduğu durumda da yine daha kısa progresyonsuz sağkalım $(H R=1,79, \% 95, C l=1,46-2,20)$ ve genel sağkalım $(H R=1,97, \% 95, C l=1,61-2,40)$ olduğu saptanmıştır. Subgrup analizde de NLR ve PLR için kesme noktası ne kadar yüksek alınırsa bu markırların prediktif etkilerinin o kadar güçlü olduğu bildirmişlerdir. Williams ve ark. [20] yaptığı çalışmaya 519 over kanserli hasta alınmıştır. İleri evre, kötü diferansiye hastalarda NLR oranı daha yüksek olduğunu saptamışlardır. Bizim çalışmamızda NLR oranının evre ve grad ile istatistiksel olarak anlamlı ilişkisi yoktu. Cho ve ark. [23] yaptığı çalışmada NLR oranının kötü prognostik faktör olduğu bildirilmiştir.

Bizim çalışmamızda PLR'nin genel sağkalımla istatiksel olarak anlamlı ilişkisi mevcuttu $(p=0,011)$. Asher ve ark. [24] yaptığı çalışmaya 235 hasta alınmıştır. NLR ve PLR oranlarının kötü prognostik faktör olduğu bildirilmiştir. Zhang ve ark. [25] yaptığı çalışmada da preoperatif olarak over kanserli hastalarda bakılan PLR oranının CA 125, NLR, fibrinojen, CRP ve albümin değerlerine göre daha üstün olduğunu bildirmişlerdir. Tian ve ark. [26] yaptığı meta analizde 3574 hasta alınmış. PLR yüksek hastalarda daha kısa progresyonsuz sağkalım ve genel sağkalım olduğunu göstermişlerdir.

CRP/Alb oranının hem progresyonsuz sağkalım hem de genel sağkalım ile istatiksel olarak anlamlı ilişkisi mevcuttu (sırasıyla $p=0,011 ; p=0,008)$. Liu ve ark. [19] yaptığı çalışmada 200 hasta retropektif ve preoperatif olarak incelenmiş. Yüksek CRP/Alb oranının daha kötü genel sağkalımla ilişkili olduğu gösterilmiştir. CRP/Alb oranının ise evre ile istatiksel olarak anlamlı ilişkisi mevcuttu $(p=0,016)$. Ileri evrelerde daha yüksek CRP/ Alb değeri mevcuttu. Liu ve ark. [27] yaptığı çalışmada da CRP/Alb oranının evre ile ilişkili olduğunu bildirmişlerdir. Komura ve ark. [28] yaptığı çalışmada da CRP/Alb oranının yüksek olması daha kötü sağkalımla ilişkili bulunmuştur. CRP/Alb oranının CRP'ye göre daha iyi sağkalımı predikte ettiği bildirilmiştir. Peree ve ark. [29] yaptığı çalışmada 1091 over kanser tanılı hasta ve 1951 kontrol grubu karşılaştırıldığında over kanserli hastalarda kontrol grubunda CRP değerinde istatiksel olarak anlamlı yükseklik saptamışlardır.

Over Kanserinde Trombosit/Lenfosit, CRP/ Alb oranları prognoz üzerine etkili olduğu gösterilmiştir ancak bu verilerin retrospektif olması ve hasta sayısının düşük olması çalışmanın sınırıııklarını göstermektedir. Ancak bu oranların gelecekte farklı tedavi gruplarını oluştuturken hastaların seçiminde yardımcı olabileceği kanısındayız.

Çıkar ilişkisi: Yazarlar çıkar ilişkisi olmadığını beyan eder.

\section{Kaynaklar}

1. Siegel RL, Miller KD, Jemal A. Cancer statistics, 2020. CA Cancer J Clin 2020;70:7-30. https://doi. org/10.3322/caac. 21590

2. Morgan JrRJ, Armstrong DK, Alvarez RD, et al. Ovarian cancer, version 1.2016, NCCN clinical practice guidelines in oncology. J Natl Compr Cancer Netw 2016;14:1134-163. https://doi.org/10.6004/ jnccn.2016.0122

3. Holschneider $\mathrm{CH}$, Berek JS. Ovarian cancer: epidemiology, biology, and prognostic factors. Seminars in Surgical Oncology 2000;19:3-10. https:// doi.org/10.1002/1098-2388(200007/08)19:1<3::AIDSSU2>3.0.CO;2-S

4. Modugno F, Ness RB, Allen GO, Schildkraut JM, Davis FG, Goodman MT. Oral contraceptive use, reproductive history, and risk of epithelial ovarian cancer in women with and without endometriosis. Am J Obstet Gynecol. 2004;191:733-740. https://doi. org/10.1016/j.ajog.2004.03.035

5. Hainaut $P$, Plymoth $A$. Targeting the hallmarks of cancer: towards a rational approach to next-generation cancer therapy. Curr Opin Oncol 2013;25:50-51. https://doi.org/10.1097/CCO.0b013e32835b651e

6. Balkwill F, Mantovani A. Inflammation and cancer: back to Virchow? Lancet 2001;357:539-545. https://doi. org/10.1016/S0140-6736(00)04046-0 
7. Nie W, Yu T, Sang Y, Gao X. Tumor-promoting effect of IL-23 in mammary cancer mediated by infiltration of M2 macrophages and neutrophils in tumor microenvironment. Biochem Biophys Res Commun 2017;482:1400-1406. https://doi.org/10.1016/j. bbrc. 2016.12 .048

8. He W, Yin C, Guo G, et al. Initial neutrophil lymphocyte ratio is superior to platelet lymphocyte ratio as an adverse prognostic and predictive factor in metastatic colorectal cancer. Med Oncol 2013;30:439. https://doi. org/10.1007/s12032-012-0439-x

9. Jung MR, Park $Y K$, Jeong $O$, et al. Elevated preoperative neutrophil to lymphocyte ratio predicts poor survival following resection in late stage gastric cancer. J Surg Oncol 2011;104:504-10. https://doi. org/10.1002/jso.21986

10. Liu X, Qu JK, Zhang J, et al. Prognostic role of pretreatment neutrophil to lymphocyte ratio in breast cancer patients: a meta-analysis. Medicine 2017;96:e8101. https://doi.org/10.1097/ MD.0000000000008101

11. Gu XB, Tian T, Tian XJ, Zhang XJ. Prognostic significance of neutrophil-tolymphocyte ratio in nonsmall cell lung cancer: a meta-analysis. Sci Rep 2015;5:12493. https://doi.org/10.1038/srep12493

12. Yodying $H$, Matsuda $A$, Miyashita $M$, et al. Prognostic significance of neutrophil-to-lymphocyte ratio and platelet-to-lymphocyte ratio in oncologic outcomes of esophageal cancer: a systematic review and metaanalysis. Ann Surg Oncol 2016;23:646-654. https://doi. org/10.1245/s10434-015-4869-5

13. Baert T, Van Camp J, Vanbrabant L, et al. Influence of CA125, platelet count and neutrophil to lymphocyte ratio on the immune system of ovarian cancer patients. Gynecol Oncol 2018;150:31-37. https://doi. org/10.1016/j.ygyno.2018.05.004

14. Zhu Y, Zhou S, Liu Y, Zhai L, Sun X. Prognostic value of systemic inflammatory markers in ovarian Cancer: a PRISMA-compliant meta-analysis and systematic review. BMC Cancer 2018;18:443. https://doi. org/10.1186/s12885-018-4318-5

15. Marnell L, Mold C, Du Clos TW. C-reactive protein: ligands, receptors and role in inflammation. Clin Immunol 2005;117:104-111. https://doi.org/10.1016/j. clim.2005.08.004

16. Hefler LA, Concin N, Hofstetter G, et al. Serum $\mathrm{C}$-reactive protein as independent prognostic variable in patients with ovarian cancer. Clin Cancer Res 2008;14:710-714. https://doi.org/10.1158/1078-0432. CCR-07-1044

17. Zeng $\mathrm{F}$, Wei $\mathrm{H}$, Yeoh E, et al. Inflammatory markers of CRP, IL6, TNFalpha, and soluble TNFR2 and the risk of ovarian cancer: a meta-analysis of prospective studies. Cancer Epidemiol Biomark Prev 2016;25:1231-1239. https://doi.org/10.1158/1055-9965.EPI-16-0120

18. Brower V. Feeding the flame: new research adds to role of inflammation in cancer development. J Natl Cancer Inst 2005;97:251-253. https://doi.org/10.1093/ jnci/97.4.251

19. Milne K, Alexander C, Webb JR, et al. Absolute lymphocyte count is associated with survival in ovarian cancer independent of tumor-infiltrating lymphocytes. J Transl Med 2012;10:33. https://doi.org/10.1186/14795876-10-33

20. Williams KA, Intidhar LG, Terry KL, et al. Prognostic significance and predictors of the neutrophiltolymphocyteratio in ovarian cancer. Gynecol Oncol 2014;132:542-550. https://doi.org/10.1016/j. ygyno.2014.01.026

21. Wang $Y Q$, Jin $C$, Zheng $H M$, et al. A novel prognostic inflammation score predicts outcomes in patients with ovarian cancer. Clin Chim Acta 2016;456:163-169. https://doi.org/10.1016/j.cca.2016.03.013

22. Yin $X$, Wu L, Yang H, Yang HB. Prognostic significance of neutrophil-lymphocyte ratio (NLR) in patients with ovarian cancer: a systematic review and meta-analysis. Medicine (Baltimore) 2019;98:e17475. https://doi. org/10.1097/MD.0000000000017475

23. Cho H, Hur HW, Kim SW, et al. Pre-treatment neutrophil to lymphocyte ratio is elevated inepithelial ovarian cancer and predicts survival after treatment. Cancer Immunol Immunother 2009;58:15-23. https:// doi.org/10.1007/s00262-008-0516-3

24. Asher V, Lee J, Innamaa A, Bali A. Preoperative platelet lymphocyte ratio as an independent prognostic marker in ovarian cancer. Clin Translat Oncol 2011;13:499503. https://doi.org/10.1007/s12094-011-0687-9

25. Zhang WW, Liu KJ, Hu GL, Liang WJ. Preoperative platelet/lymphocyte ratio is a superiorprognostic factor compared to other systemic inflammatory responsemarkers in ovarian cancer patients. Tumour Biol 2015;36:8831-8837. https://doi.org/10.1007/ s13277-015-3533-9

26. Tian C, Song W, TianX, Sun Y. Prognostic significance of platelet-to-lymphocyte ratio in patients with ovarian cancer: a meta-analysis. Eur J Clin Invest 2018;48:e12917. https://doi.org/10.1111/ eci. 12917

27. Liu Y, Chen S, Zheng C, et al. The prognostic value of the preoperative c-reactive protein/albumin ratio in ovarian cancer. BMC Cancer 2017;17:285. https://doi. org/10.1186/s12885-017-3220-x

28. Komura N, Mabuchi S, Shimura K, Kawano M, Matsumoto $Y$, Kimura T. Significance of pretreatment C-reactive protein, albumin, and C-reactive protein to albumin ratio in predicting poor prognosis in epithelial Ovarian Cancer Patients. Nutr Cancer 2020:1-8. https://doi.org/10.1080/01635581.2020.1798479 
29. Peres LC, Mallen AR, Townsend MK, et al. High levels of $\mathrm{C}$-reactive protein are associated with an increased risk of ovarian cancer: results from the Ovarian Cancer Cohort Consortium. Cancer Res 2019;79:5442-5451. https://doi.org/10.1158/0008-5472.CAN-19-1554

Etik kurul onayı: Pamukkale Üniversitesi Tıp Fakültesi Girişimsel Olmayan Klinik Araştırmalar Etik Kurulu'nun 16.04.2020 tarih ve 20/26610 karar sayısı ile yerel etik onayı alındı.

\section{Yazarların makaleye olan katkıları}

B.Y.T. ve A.G.D. çalışmanın ana fikrini ve hipotezini kurgulamışlardır. S.D. teoriyi geliştirmiş ve E.A., C.K., B.Ç.D. ile birlikte gereç ve yöntem bölümünü düzenlemişlerdir. Sonuçlar kısmındaki verilerin değerlendirmesini A.E. yapmıştır. Makalenin tartışma bölümü B.Y.T., T.D., M.Ö. ve D.K. tarafından yazılmış, G.G.D. ve A.Y. gözden geçirip gerekli düzeltmeleri yapmış ve onaylamıştır. Ayrıca tüm yazarlar çalışmanın tamamını tartışmış ve son halini onaylamıştır. 